\title{
Metformin induces oxidative stress in white adipocytes and raises uncoupling protein 2 levels
}

\author{
Andrea Anedda, Eduardo Rial and M Mar González-Barroso \\ Department of Cellular and Molecular Physiopathology, Centro de Investigaciones Biológicas, CSIC, Ramiro de Maeztu 9, 28040 Madrid, Spain \\ (Correspondence should be addressed to M M González-Barroso; Email: margb@cib.csic.es)
}

\begin{abstract}
Metformin is a drug widely used to treat type 2 diabetes. It enhances insulin sensitivity by improving glucose utilization in tissues like liver or muscle. Metformin inhibits respiration, and the decrease in cellular energy activates the AMPactivated protein kinase that in turn switches on catabolic pathways. Moreover, metformin increases lipolysis and $\beta$-oxidation in white adipose tissue, thereby reducing the triglyceride stores. The uncoupling proteins (UCPs) are transporters that lower the efficiency of mitochondrial oxidative phosphorylation. UCP2 is thought to protect against oxidative stress although, alternatively, it could play an energy dissipation role. The aim of this work was to analyse the involvement of UCP2 on the effects of metformin in white adipocytes. We studied the effect of this drug in
\end{abstract}

differentiating 3T3-L1 adipocytes and found that metformin causes oxidative stress since it increases the levels of reactive oxygen species (ROS) and lowers the aconitase activity. Variations in UCP2 protein levels parallel those of ROS. Metformin also increases lipolysis in these cells although only when the levels of ROS and UCP2 have decreased. Hence, UCP2 does not appear to be needed to facilitate fatty acid oxidation. Furthermore, treatment of C57BL/6 mice with metformin also augmented the levels of UCP2 in epididymal white adipose tissue. We conclude that metformin treatment leads to the overexpression of UCP2 in adipocytes to minimize the oxidative stress that is probably due to the inhibition of respiration caused by the drug.

Journal of Endocrinology (2008) 199, 33-40

\section{Introduction}

The uncoupling proteins (UCPs) are carriers that belong to the protein superfamily constituted by the metabolite transporters of the mitochondrial inner membrane. In mammals, there are five genes that encode proteins considered to be UCP1 (Ledesma et al. 2002, Krauss et al. 2005). UCP1 is present in brown adipose tissue and it is the only member of the family whose physiological function and regulation have been firmly established. UCP1 is a proton transporter activated by fatty acids and it is involved in non-shivering thermogenesis (Rial \& Gonzalez-Barroso 2001). UCP2 is ubiquitously expressed while UCP3 is only found in skeletal muscle and brown adipose tissue. UCP4 (currently known as SLC25A27) and UCP5 (currently known as SLC25A14) are predominantly expressed in the nervous system. The physiological roles of UCP2 and UCP3 are not fully understood (Cannon et al. 2006, Bézaire et al. 2007). According to their family name, these proteins should lower the efficiency of the mitochondrial oxidative phosphorylation by allowing a regulated discharge of the proton gradient.

The superoxide anion, the hydroxyl radical or hydrogen peroxide are highly reactive molecules that are collectively termed reactive oxygen species (ROS). ROS can chemically modify membranes, proteins or DNA and therefore high
ROS levels can lead to a variety of pathologies (Halliwell \& Gutteridge 1999, Lenaz 2001). Thus, in resting (state 4) conditions, when oxygen consumption is low and the protonmotive force ( $\mathrm{pmf}$ ) is high, the rate of superoxide formation is at its maximum. However, an increase in the respiratory rate, due to an increase in ATP demand for example, will diminish the formation of ROS (Brookes 2005).

$\mathrm{UCP} 2$ is upregulated in a number of physiological situations where there is oxidative stress. The mitochondrial respiratory chain is probably the most important source of superoxide and its rate of formation depends on respiratory activity. UCP2 could contribute to the protection against oxidative damage by increasing the membrane proton conductance and accelerating respiration. In fact, the first phenotype described for the UCP2 knock-out mouse was an increased resistance to infection by toxoplasma, which correlated with higher levels of ROS in macrophages (Arsenijevic et al. 2000). Steatotic livers have also chronically elevated levels of ROS and a higher expression of UCP2 (Evans et al. 2008). The increased expression of UCP2 and diminished susceptibility to oxidative stress in certain drug-resistant tumour cell lines are also noteworthy (Harper et al. 2002).

Diabetes is a disease characterized by a chronic elevation of the circulating glucose levels, which has toxic effects on a 
variety of organs and tissues like kidney, retina, cardiovascular and nervous systems, etc. Elevated glucose levels are also toxic for $\beta$-cells, which progressively lose their ability to secrete insulin thereby worsening the situation (Newsholme et al. 2007). It is now widely accepted that hyperglycaemia causes oxidative stress and that $\beta$-cells are particularly susceptible to oxidative damage (Green et al. 2004). In these cells, UCP2 appears to play a dual role. While UCP2 could be part of the antioxidant defence system, as in other cells (Krauss et al. 2005, Affourtit \& Brand 2008), there is also evidence that UCP2 may participate in the control of insulin secretion. Indeed, UCP2-deficient mice are hypoglycaemic due to increased glucose-stimulated insulin secretion associated with higher islet ATP levels (Zhang et al. 2001), while insulin levels are low in models of UCP2 overexpression (Chan et al. 1999, 2001, Hong et al. 2001). Thus, variations in UCP2 expression and/or activity could contribute to $\beta$-cell dysfunction and to the development of diabetes (Affourtit \& Brand 2008).

Metformin (dimethylbiguanidine) is widely used to treat type 2 non-insulin-dependent diabetes mellitus (Bailey et al. 1996, Kirpichnikov et al. 2002). It is an insulin-sensitizing agent that has beneficial effects not only on glycaemic levels but also in the cardiovascular system. However, the mode of action of metformin has yet to be fully established. In muscle, liver and endothelial cells, the metabolic changes induced by metformin appear to be mediated by the AMP-activated protein kinase (AMPK). AMPK acts as a sensor of the cellular energy status, being switched on by an increased ATP demand or by processes that interfere with ATP production like ischaemia. The activated form of AMPK switches on catabolic pathways while switching off ATP-consuming processes (Hardie et al. 2006). It has been reported that metformin binds to complex I of the mitochondrial respiratory chain and this could in part explain how this drug acts (Owen et al. 2000). The inhibition of complex I would cause a decrease in energy supply that would in turn lead to a higher AMP/ATP ratio, and the concomitant activation of AMPK.

In white adipose tissue, metformin also stimulates catabolic pathways through the activation of AMPK, reducing the triglyceride stores as reflected by the smaller size of the adipocytes (Lenhard et al. 1997, Huypens et al. 2005). These effects are achieved through an increase in lipolysis and $\beta$-oxidation, which would imply that there is no release of fatty acids and that they are oxidized within the adipocyte. In this respect, it must be emphasized that metformin also causes an increase in mitochondrial mass (Lenhard et al. 1997). This situation would be similar to that caused by leptin, a hormone involved in the control of energy balance that increases energy expenditure and suppresses appetite (Ahima \& Flier 2000). Hyperleptinaemia decreases the mRNA levels of lipogenic enzymes while it increases those involved in lipolysis (Zhou et al 1997, Ceddia et al. 2000), and the fatty acids released are oxidized inside the adipocyte instead of being exported to other tissues (Wang et al. 1999). Interestingly, UCP2 expression is also induced under those conditions. These effects of leptin require an increase in the expression of the peroxisomal proliferation-activated receptor $\alpha$, a well-known upregulator of mitochondrial biogenesis (Lee et al. 2002).

The aim of the present study was to determine whether UCP2 is involved in the action of metformin on white adipocytes. The working hypothesis was that UCP2 could be overexpressed either to uncouple respiration to facilitate fatty acid oxidation or to minimize the generation of ROS that would be due to the inhibition of complex I. The data obtained demonstrate that metformin causes oxidative stress in the adipocyte cell line 3T3-L1 and that as a result UCP2 is overexpressed as part of the antioxidant defence response.

\section{Materials and Methods}

\section{Materials}

All materials were obtained from Sigma-Aldrich unless otherwise stated. Cell culture media, antibiotics and bovine serum were from Gibco/Invitrogen. The UCP2 antibody was from Santa Cruz Biotechnology (Santa Cruz, CA, USA) while the antibody against porin was from Sigma-Aldrich.

\section{Experimental animals and treatments}

Adult C57BL/6 male mice (14 weeks old) weighing 25-30 g were used in this study. Twenty mice were maintained at $22{ }^{\circ} \mathrm{C}$ with a $12 \mathrm{~h}$ light: $12 \mathrm{~h}$ darkness cycle, and with access to food and water ad libitum. Ten mice were injected intraperitoneally daily with a dose of metformin (250 mg $/ \mathrm{kg}$ of body weight) for 3 days, while ten control mice received $0.9 \%$ saline. On the last day, the mice were killed $1 \mathrm{~h}$ after the injection. Liver, spleen, epididymal white adipose tissue and hind limb skeletal muscle were recovered from the mice and immediately frozen in liquid nitrogen. All procedures were performed in accordance with the European regulations for the protection of animals used for experimental and other scientific purposes.

\section{Cell culture and differentiation}

3T3-L1 mouse embryo fibroblasts were obtained from the American Type Culture Collection (Mansassas, VA, USA). Cells were cultured in a humidified atmosphere at $37^{\circ} \mathrm{C}$ and $5 \% \mathrm{CO}_{2}$ in Dulbecco's modified Eagle's medium (DMEM) containing $10 \%(\mathrm{v} / \mathrm{v})$ heat-inactivated bovine serum supplemented with penicillin $(100 \mathrm{U} / \mathrm{ml})$ and streptomycin $(100 \mu \mathrm{g} / \mathrm{ml})$. When the cells reached confluence, the culture medium was switched to DMEM supplemented with $10 \%$ $(\mathrm{v} / \mathrm{v})$ heat-inactivated foetal bovine serum (FBS) plus antibiotics. Two days after they reached confluence (day 2), $1 \mathrm{mM}$ 3-isobutyl-1-methylxanthine (IBMX), $1 \mu \mathrm{M}$ insulin and $1 \mu \mathrm{M}$ dexamethasone were added to the medium to induce their differentiation to adipocytes. After 3 days (day 5), this medium was replaced by fresh DMEM/10\% FBS 
containing only $1 \mu \mathrm{M}$ insulin. From day 7 , the cells were subjected to the different treatments in DMEM/10\% FBS.

Preparation of mitochondria-enriched extracts from mouse tissues

Mitochondria-enriched fractions were prepared from liver, spleen, epididymal white adipose tissue and hind limb skeletal muscle. Liver, spleen and white adipose tissue were homogenized in $250 \mathrm{mM}$ sucrose, $1 \mathrm{mM}$ EDTA and $10 \mathrm{mM}$ Tris- $\mathrm{HCl}$ $(\mathrm{pH} 7 \cdot 4)$ plus $0 \cdot 1 \%(\mathrm{v} / \mathrm{v})$ of the mammalian protease inhibitor cocktail from Sigma-Aldrich. Homogenates were centrifuged at $10000 \mathrm{~g}$ for $10 \mathrm{~min}$ at $4{ }^{\circ} \mathrm{C}$, and the pellet obtained was resuspended and centrifuged at $750 \mathrm{~g}$ for $10 \mathrm{~min}$. The supernatant was collected and spun at $10000 \mathrm{~g}$ for $20 \mathrm{~min}$, and the final pellet was resuspended in 10-30 $\mu$ l of the isolation buffer. The mitochondrial-enriched fractions from muscle were prepared after mincing the tissue in $100 \mathrm{mM}$ sucrose, $46 \mathrm{mM}$ $\mathrm{KCl}, 2 \mathrm{mM}$ EDTA and $10 \mathrm{mM}$ Tris- $\mathrm{HCl}(\mathrm{pH} 7 \cdot 4)$ supplemented with the protease inhibitor cocktail. The tissue was homogenized and spun at $500 \mathrm{~g}$ for $10 \mathrm{~min}$, and the supernatant was collected and spun for $10 \mathrm{~min}$ at $10000 \mathrm{~g}$. The pellet was finally resuspended in 10-30 $\mu \mathrm{l}$ of the same buffer.

PBS-washed 3T3-L1 adipocytes were suspended in a buffer containing $250 \mathrm{mM}$ sucrose, $0.1 \mathrm{mM}$ EDTA and $5 \mathrm{mM}$ HEPES $(\mathrm{pH} 7 \cdot 4)$ plus $0 \cdot 1 \%(\mathrm{v} / \mathrm{v})$ of the protease inhibitor cocktail. Cells were subjected to three freeze/thaw cycles and centrifuged at $750 \mathrm{~g}$ for $10 \mathrm{~min}$, the supernatant collected and centrifuged at $10000 \mathrm{~g}$ for $20 \mathrm{~min}$. The pellet obtained was resuspended in 10-20 $\mu \mathrm{l}$ of the same buffer. In all cases, the protein concentration was determined by the bicinchoninic acid assay using BSA as standard.

\section{Oil red $O$ staining and cell mass determination}

Differentiation of 3T3-L1 cells was assessed by Oil red O staining on day 12. Cells were washed with cold PBS and fixed in $4 \%$ paraformaldehyde for $1 \mathrm{~h}$. Dishes were rinsed with $60 \%$ isopropanol, dried and the cells were stained for 10 min with $0 \cdot 2 \%$ Oil red $\mathrm{O}$ in isopropanol/water (6:4). After extensive washes with distilled water, the Oil red $\mathrm{O}$ was eluted by adding $100 \%$ isopropanol and the dye was quantified by measuring the absorbance at $500 \mathrm{~nm}$ (Ramírez-Zacarías et al. 1992). Cell mass was assessed from the protein recovered from individual $100 \mathrm{~mm}$ diameter Petri dishes. Cells were washed with PBS and scrapped from the dishes, centrifuged at $2000 \mathrm{~g}$ for $5 \mathrm{~min}$ and resuspended in $1 \mathrm{ml} 250 \mathrm{mM}$ sucrose, $0 \cdot 1 \mathrm{mM}$ EDTA and $5 \mathrm{mM}$ HEPES (pH 7.4) plus $0 \cdot 1 \%(\mathrm{v} / \mathrm{v})$ of the protease inhibitor cocktail. Protein was determined by the bicinchoninic acid assay.

\section{Western blot analysis}

About 30-60 $\mu \mathrm{g}$ of the mitochondrial extracts were resolved by SDS-PAGE and then transferred to membranes that were probed with either an anti-UCP2 antibody or a mouse antiporin antibody used as a loading control. The immunoblots were developed by enhanced chemiluminescence (GE
Healthcare, Little Chalfont, UK), and the band intensity was recorded using the CCD camera of a Fujifilm LAS-3000 analyzer and quantified with the Fujifilm MultiGauge programme, (Fuji Photo Film GmbH, Düsseldorf, Germany).

\section{Aconitase activity}

Aconitase activity was determined using the in-gel assay described by Tong et al. (2003). Adipocytes were lysed in a buffer containing $0.08 \%$ digitonin, $210 \mathrm{mM}$ mannitol, $70 \mathrm{mM}$ sucrose, $4 \mathrm{mM}$ HEPES (pH 7.2) and $0 \cdot 1 \%$ of Sigma's protease inhibitor cocktail, for $10 \mathrm{~min}$ at $4{ }^{\circ} \mathrm{C}$. The lysate was centrifuged at $750 \mathrm{~g}$ for $10 \mathrm{~min}$, and the supernatant was collected and then centrifuged again at $7000 \mathrm{~g}$ for $10 \mathrm{~min}$. The pellet was resuspended in a buffer containing $20 \mathrm{mM}$ Tris- $\mathrm{HCl}(\mathrm{pH} 8 \cdot 8), 137 \mathrm{mM} \mathrm{NaCl}, 10 \%$ v/v glycerol and $1 \%$ $(\mathrm{v} / \mathrm{v})$ Triton X-100, and the samples resolved by PAGE under non-denaturing conditions. The gel was incubated in the darkness at $37^{\circ} \mathrm{C}$ for $30 \mathrm{~min}$ in a buffer containing $1.2 \mathrm{mM}$ methylthiazoletetrazolium, $0.3 \mathrm{mM}$ phenazine methosulphate and $5 \mathrm{U} / \mathrm{ml}$ isocitrate dehydrogenase. The enzyme activity was then recorded using the CCD camera of a Fujifilm LAS-3000 analyzer and quantified with the Fujifilm MultiGauge programme.

\section{Analysis of the levels of ROS}

Adipocytes were trypsinized and resuspended in DMEM containing $1 \%$ FBS at a concentration of one million cells per $\mathrm{ml}$. Cells were incubated in the presence of $5 \mu \mathrm{M}$ dihydroethidium (DHE) for $30 \mathrm{~min}$ at $37^{\circ} \mathrm{C}$ in the darkness. Samples were washed twice in the same medium and the fluorescence analysed using an EPICS XL flow cytometer.

\section{Lipolysis assay}

Lipolysis was estimated from the release of glycerol using Wieland's method (Wieland 1974). After each treatment $50 \mu \mathrm{l}$ of the culture medium were mixed with $950 \mu \mathrm{l}$ reaction mixture containing $1.23 \mathrm{mM}$ ATP, $0.56 \mathrm{mM} \mathrm{NAD}, 5 \mathrm{U} / \mathrm{ml}$ glycerophosphate dehydrogenase, $350 \mathrm{U} / \mathrm{ml}$ glycerokinase, $1 \mathrm{M}$ hydrazine hydrate, $0 \cdot 2 \mathrm{M}$ glycine and $2 \mathrm{mM} \mathrm{MgCl}_{2}$. The samples were incubated for $40 \mathrm{~min}$ at room temperature and the absorbance at $340 \mathrm{~nm}$ was then determined.

\section{Statistical analysis}

All results are shown as the mean \pm s.E.M. of data from at least three independent experiments. The statistical significance of the differences was calculated using Student's $t$-test, and values of $P<0.05$ were accepted as statistically significant.

\section{Results}

\section{Adipocyte differentiation and metformin treatments}

Conditions were established to induce the differentiation of the 3T3-L1 cells from fibroblastic progenitors to mature 
adipocytes. The differentiation protocol included their growth for 3 days (from day 2 to 5 ) in medium supplemented with IBMX, insulin and dexamethasone followed by another 2 days in the presence of insulin. Between day 9 and 12, more than $90 \%$ of the fibroblasts had differentiated into mature adipocytes with a multilocular distribution of the triglyceride droplets. On day 7 of differentiation, the cultures were divided into four groups: control, insulin $(1 \mu \mathrm{M})$, metformin $(4 \mathrm{mM})$ and metformin plus insulin. The cells were collected and characterized on days 7 (prior to any treatment), 9 and 12 . On day 12, dishes treated with metformin presented lower cell mass as revealed from the total protein recovered from the dishes (Fig. 1E). Additionally, metformin-treated cells appeared to be less differentiated than control or insulintreated ones (Fig. 1). The effect of metformin was also reflected in a lower triglyceride content, as revealed by Oil red $\mathrm{O}$ staining (Fig. 1F). The presence of insulin in the metformin-treated cells improved the degree of differentiation. When metformin was added at the beginning of the differentiation protocol, adipogenesis was markedly inhibited (data not shown).

\section{Metformin causes oxidative stress in 3T3-L1 adipocytes}

If metformin binds to complex I of the respiratory chain and inhibits electron transfer, an increase in ROS production would be expected. Thus, the action of metformin would resemble that of rotenone. The ROS levels in 3T3-L1 cells were measured with the fluorescent probe DHE and they were compared with the values obtained in the presence of rotenone as a reference (Fig. 2A). As expected, the addition of rotenone to control cells produced a threefold increase in DHE fluorescence. While the ROS levels did not vary in control or insulin-treated cells, metformin treatment caused a marked increase in ROS, which was most evident on day 9 when it almost reached the rotenone values. ROS damage was assessed by measuring the activity of the mitochondrial enzyme aconitase. Accordingly, while control or insulintreated cells showed almost constant aconitase activity during the 5 days of treatment, the presence of metformin caused a decrease close to $50 \%$ in the activity of this enzyme (Fig. 2B).

\section{Metformin causes an increase in UCP2 levels}

Since many reports indicate that UCP2 is overexpressed when oxidative stress increases, the expression of this protein was examined. UCP2 expression is controlled at both the transcriptional and translational levels and in several instances, the variations in the mRNA and protein levels are not correlated (Pecqueur et al. 2001). Therefore, we determined the levels of UCP2 protein by immunoblotting in mitochondria-enriched extracts and found that the variations in UCP2 levels paralleled those of ROS. Thus, while UCP2 was barely detected in control adipocytes, the treatment with metformin caused a marked increase in its expression that peaked on day 9 (Fig. 2C and D). Insulin did not alter the
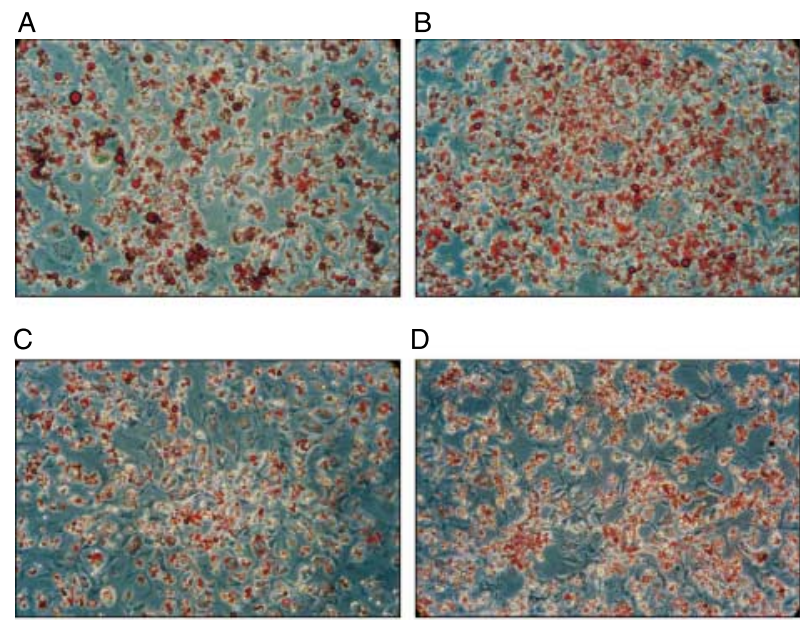

D
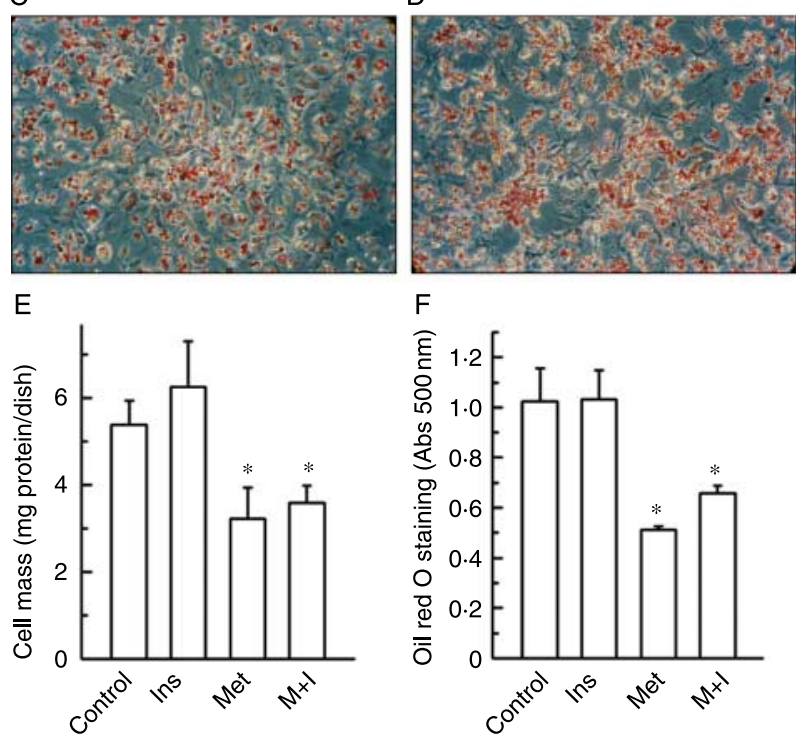

$\mathrm{F}$

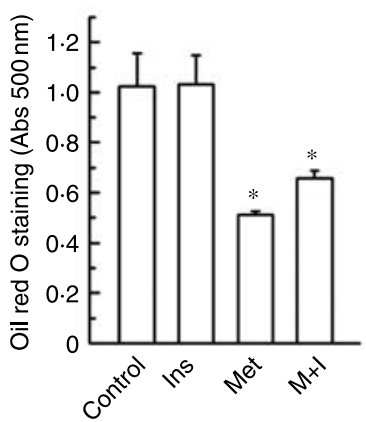

Figure 1 Effect of metformin and insulin on the differentiation of 3T3-L1 cells after 12 days of differentiation. Representative Oil red $\mathrm{O}$ staining of the cultured cells. From day 7 , cells were maintained in culture medium DMEM plus 10\% FBS under the following conditions: (A) control cells with no further additions, (B) medium supplemented with $1 \mu \mathrm{M}$ insulin, (C) $4 \mathrm{mM}$ metformin, (D) $1 \mu \mathrm{M}$ insulin plus $4 \mathrm{mM}$ metformin, (E) cell mass expressed as the protein recovered from individual Petri dishes and (F) quantification of Oil red $\mathrm{O}$ staining. Results are expressed as means \pm s.E.M. of at least three independent experiments. Conditions are Control; Ins, $1 \mu \mathrm{M}$ insulin; Met, $4 \mathrm{mM}$ metformin; $\mathrm{M}+\mathrm{I}, 1 \mu \mathrm{M}$ insulin plus $4 \mathrm{mM}$ metformin. ${ }^{*} P<0 \cdot 05$ of the experimental condition versus the control cells.

expression of UCP2. Interestingly, mRNA levels did not vary under any of our experimental conditions (data not shown).

\section{UCP2 expression does not correlate with the lipolytic activity in} 3T3-L1 adipocytes

The expression of UCP2 is sometimes linked to an increase in fatty acid oxidation. Indeed, hyperleptinaemia induces lipolysis and raises the levels of fatty acid oxidation enzymes, as well as those of UCP2 (Zhou et al. 1997). We determined the rate of lipolysis under our conditions by measuring the release of glycerol into the medium. Differentiation led to an increase in glycerol release on day 9, which was similar under the four conditions studied (Fig. 3). However, on day 12, metformin-treated cells showed a $70 \%$ increase in lipolysis 

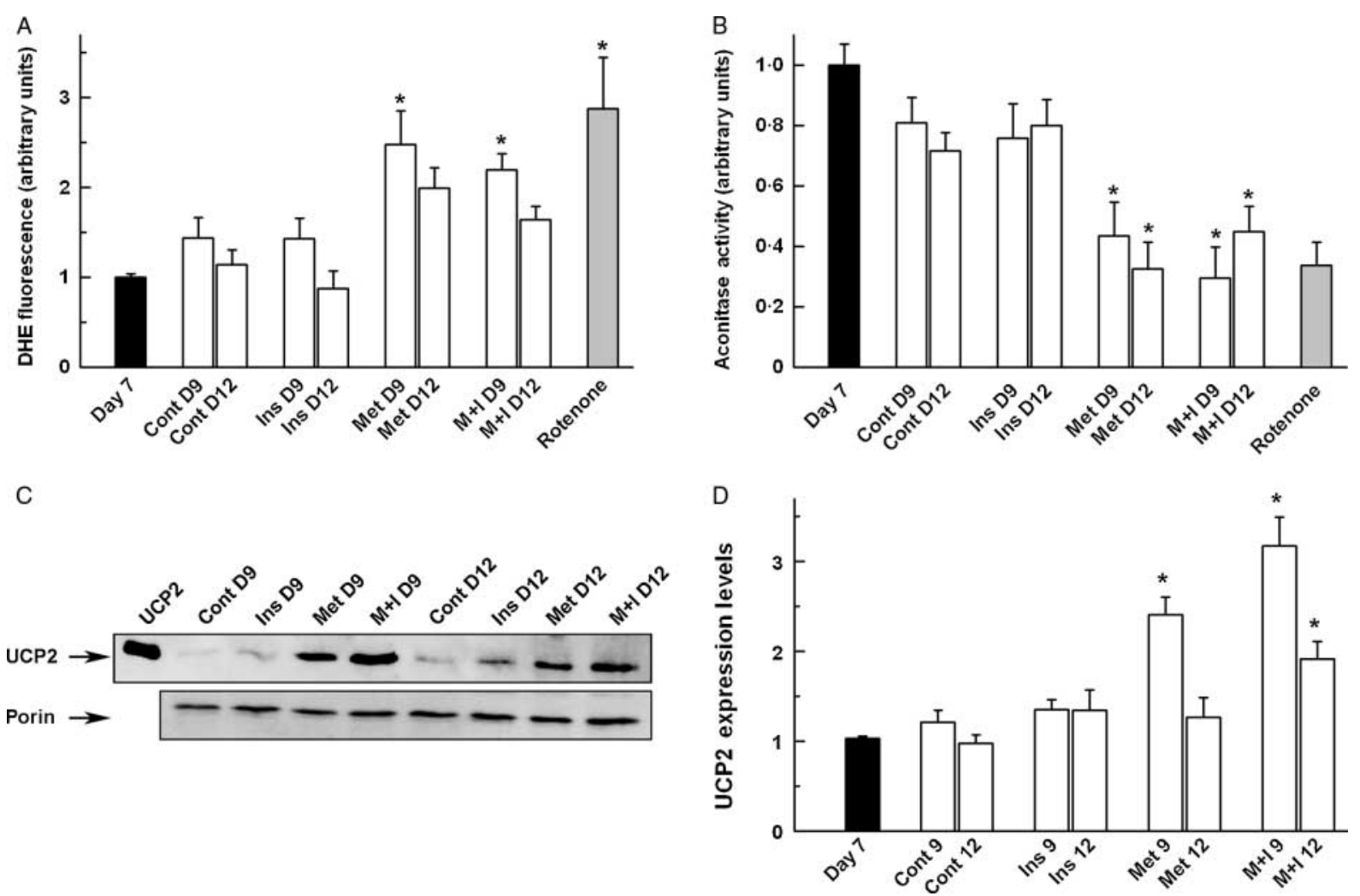

Figure 2 Metformin causes oxidative stress in differentiating 3T3-L1 cells. Effects of metformin and insulin in oxidative stress parameters (A and B) and UCP2 protein levels (C and D) on days 9 and 12 of adipocyte differentiation. From day 7, cells were treated with either $1 \mu \mathrm{M}$ insulin (Ins), $4 \mathrm{mM}$ metformin (Met) or $1 \mu \mathrm{M}$ insulin plus $4 \mathrm{mM}$ metformin $(\mathrm{M}+\mathrm{I})$. Untreated cells were used as control (Cont). (A) ROS levels measured by flow cytometry using the fluorescent probe DHE. (B) Aconitase activity. In (A) and (B), cells treated with $4 \mu \mathrm{M}$ rotenone for $2 \mathrm{~h}$ were used as a reference. (C) Representative western blot for the expression of UCP2 under our experimental conditions (top lane). The mitochondrial protein porin was used as loading control (bottom lane). (D) Variations in the UCP2 expression levels. In all panels, data represent means \pm S.E.M. of at least three independent experiments. ${ }^{*} P<0 \cdot 05$ of the experimental condition versus the corresponding control cells of the same day.

when compared with control or insulin-treated cells. Significantly, the presence of insulin moderated the effect of metformin.

\section{Metformin induces the expression of UCP2 in mouse white adipose tissue}

To investigate whether the effects of metformin in 3T3-L1 adipocytes could also be reproduced in vivo, C57BL/6 mice were injected daily with doses of $250 \mathrm{mg}$ metformin per $\mathrm{kg}$ over 3 days. Mitochondria were isolated from tissues that could be relevant for the antidiabetic activity of the drug such as epididymal white adipose tissue, hind limb skeletal muscle and liver. Spleen mitochondria were used as control since UCP2 expression is known to be high (Pecqueur et al. 2001). While UCP2 protein levels were low in white adipose tissue from control animals, it increased markedly upon metformin treatment (Fig. 4). UCP2 protein was undetectable in either muscle or liver mitochondria from control mice or those treated with metformin (data not shown).

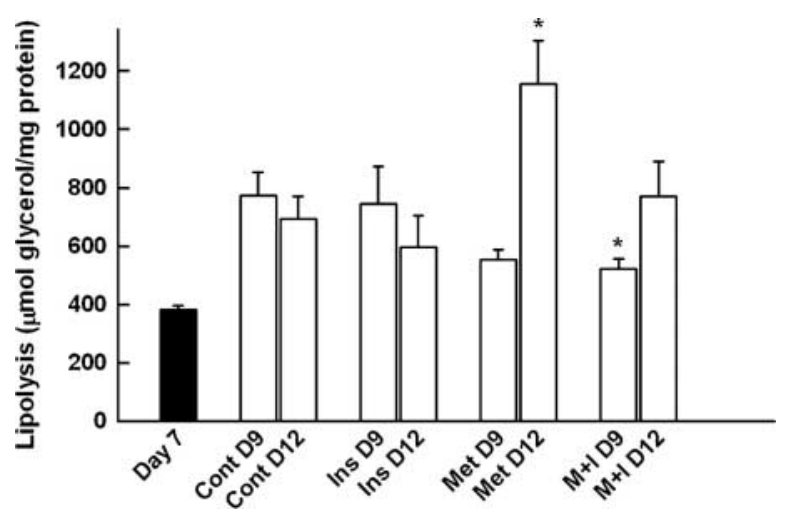

Figure 3 Metformin induces lipolysis in differentiating 3T3-L1 adipocytes. Glycerol release was used as an index of lipolysis during adipocyte differentiation under our experimental conditions. From day 7 of differentiation, cells were treated with either $1 \mu \mathrm{M}$ insulin (Ins), $4 \mathrm{mM}$ metformin (Met) or $1 \mu \mathrm{M}$ insulin plus $4 \mathrm{mM}$ metformin $(I+M)$. Untreated cells were used as control (Cont). Values are presented as means \pm S.E.M. of three to four independent experiments, performed in duplicate. ${ }^{*} P<0.05$ of the experimental condition versus the control cells of the same day. 


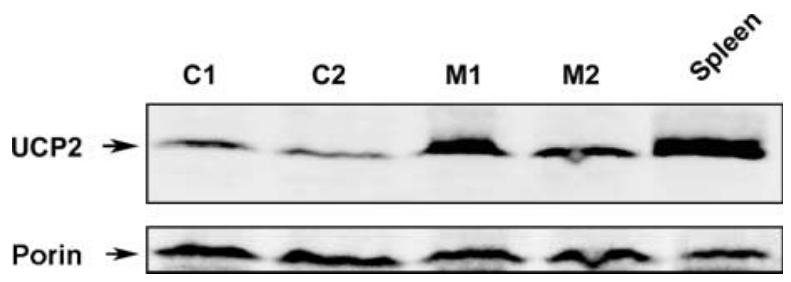

Figure 4 Metformin induces the expression of UCP2 in white adipose tissue of C57BL/6 mice. Representative western blot of UCP2 in mitochondria isolated from mice epididymal white adipose tissue. UCP2 expression in spleen mitochondria from control mice is shown as a reference. Ten mice were injected intraperitoneally with a daily dose of $0.9 \%$ saline solution for 3 days (C1, C2) while another ten mice were injected with metformin $250 \mathrm{mg} / \mathrm{kg}$ (M1, M2). Mitochondrial porin was used as loading control (bottom lane).

\section{Discussion}

ROS are highly reactive molecules that, although they can chemically damage cellular components, participate in the maintenance of cellular redox homeostasis and in signal transduction pathways (Droge 2002, Biswas et al. 2006). Cells possess detoxification systems that protect them from the harmful effects of ROS, both in the cytoplasm and in mitochondria (Matés et al. 1999, Nordberg \& Arner 2001). Oxidative stress occurs when there is an excess of ROS, due to an imbalance between its formation and degradation, which not only causes cellular damage but also alters signalling pathways. This disequilibrium is involved in or underlies a variety of human pathologies like inflammation, ischaemia/ reperfusion injury, diabetes, atherosclerosis, neurodegeneration or tumour formation (Halliwell \& Gutteridge 1999, Lenaz 2001).

Superoxide is produced in the cell by various enzyme systems although the respiratory chain makes mitochondria one of the major sources of ROS (Barja 1999, Turrens 2003). Electron transfer at complexes I and III includes steps that permit the monovalent reduction of oxygen to form the superoxide radical. The rate of mitochondrial ROS formation depends on the redox state of those sites, which in turn depends on the magnitude of the pmf: the higher the pmf, the lower the respiratory rate and the higher the rate of ROS formation. Therefore, the induction of proton leakage pathways to decrease the $\mathrm{pmf}$ is a means to diminish oxidative stress (Brookes 2005). The involvement of UCP2 as a defence mechanism against oxidative stress is well documented although evidence is largely circumstantial. Thus, UCP2 is induced under conditions of stress and its absence leads to the increase in ROS formation (Arsenijevic et al. 2000).

Nevertheless, the physiological role of UCP2 remains controversial. The upregulation of UCP2 induced by leptin, when lipolysis and $\beta$-oxidation are also promoted, could indicate that it is involved in energy dissipation (Zhou et al. 1997, Ceddia et al. 2000). This function would be similar to that of UCP1 in brown adipose tissue where uncoupling the oxidative phosphorylation converts the adipocytes into fat-burning machines (Rial \& Gonzalez-Barroso 2001). Such a role in energy dissipation could also be inferred from the effects of UCP2 in glucose-stimulated insulin secretion. When UCP2 is activated, the pmf falls, the ATP/ ADP ratio diminishes and insulin secretion decreases (Chan et al. 1999, 2001, Hong et al. 2001). The opposite is also true. When UCP2 expression decreases, insulin secretion is enhanced (Zhang et al. 2001, Bordone et al. 2006). Moreover, genetic studies have identified associations between polymorphisms in the human UCP2 promoter and type 2 diabetes as well as decreased insulin secretion (Chan \& Harper 2006). Interestingly, the novel UCP2 inhibitor genipin also increases insulin secretion (Zhang et al. 2006) and therefore UCP2 is envisaged as a novel drug target for the treatment of diabetes. However, whether the main function of UCP2 in the $\beta$-cell is to regulate insulin secretion or to protect cells from oxidative injury remains a matter of debate (Produit-Zengaffinen et al. 2007).

White adipose tissue is not only an energy storage site but also a major endocrine and secretory organ actively involved in the regulation of energy balance. Defects in adipose tissue metabolism are one of the links between obesity, insulin resistance and diabetes. Metformin is a drug used in the treatment of diabetes but its effects on white adipocyte metabolism are not fully understood. Metformin does not influence insulin secretion but rather, it helps to improve the control of glycaemia by promoting glucose utilization through an AMPK-mediated stimulation of catabolism (Bailey et al. 1996, Kirpichnikov et al. 2002). Indeed, metformin increases lipolysis and reduces triglyceride stores in adipocytes (Lenhard et al. 1997). Intriguingly, it has also been reported that AMPK activation inhibits lipolysis and induces apoptosis (Dagon et al. 2006). The inhibition of the mitochondrial complex I by metformin supposedly causes an energy deficit that decreases ATP levels and activates AMPK (Owen et al. 2000). Additionally, inhibition of complex I is known to cause an increase in superoxide production (Turrens 2003). We investigated the effect of metformin on the adipocyte cell line 3T3-L1 and observed a marked increase in ROS levels that it is also reflected in a loss of aconitase activity. These effects support the idea that the increase in ROS is due to the drug binding to complex I. Since high ROS levels prompt the response of the cellular antioxidant defences, the observed increase in UCP2 levels is consistent with its postulated role in the protection against oxidative stress. We should also point out that metformin causes a decrease in total cell mass that can be interpreted as cell death due to the stress. The increase in UCP2 protein levels occurs without changes in mRNA, a translational control of UCP2 expression that has been previously reported (Pecqueur et al. 2001). The control seems to be exerted by a 36-amino-acid sequence that is coded by an upstream open reading frame although the intracellular signals involved are yet to be defined (Hurtaud et al. 2006).

Complex I inhibition could be the primary cause of AMPK activation although an increase in UCP2 levels could 
also produce the same result. In fact, variations in the activity/expression of UCP2 in $\beta$-cells directly influence the ATP/ADP ratio and insulin secretion (Affourtit \& Brand 2008). Furthermore, ectopic expression of UCP1 in white adipose tissue decreases the cellular energy content, activates AMPK and increases lipid oxidation (Matejkova et al. 2004). We investigated the induction of lipolysis and found a marked increase in metformin-treated cells although it is only apparent after a 5-day exposure. While these results are compatible with UCP2-mediated activation of AMPK, it must be pointed out that UCP2 levels significantly decreased by day 12 and, therefore, its presence does not appear to be required for lipolysis. Our data indicate that the induction of UCP2 is a direct consequence of metformin-induced oxidative stress. It is also noteworthy that pharmacological doses of metformin raise the levels of UCP2 in murine white adipose tissue, thus providing confirmation of the relevance of our observations to the in vivo situation. Future work should be directed towards elucidating whether UCP2 is required to activate AMPK and to produce the subsequent stimulation of lipolysis.

\section{Declaration of interest}

The authors declare that there are no conflicts of interest that would prejudice the impartiality of the work reported herein.

\section{Funding}

This work was supported by two project grants from the Spanish Ministry of Science and Innovation (BFU2006-08182 and Consolider-Ingenio 2010 CSD2007-00020). A A was supported by a predoctoral fellowship from the 'Master and Back' program of the autonomous region of Sardinia (Italy). M M G B was supported by the 'Ramón y Cajal' program of the Spanish Ministry of Science and Innovation.

\section{References}

Affourtit C \& Brand MD 2008 On the role of uncoupling protein-2 in pancreatic beta cells. Biochimica et Biophysica Acta 1777 973-979.

Ahima RS \& Flier JS 2000 Leptin. Annual Review of Physiology 62 413-437.

Arsenijevic D, Onuma H, Pecqueur C, Raimbault S, Manning BS, Miroux B, Couplan E, Alves-Guerra MC, Goubern M, Surwit R et al. 2000 Disruption of the uncoupling protein-2 gene in mice reveals a role in immunity and reactive oxygen species production. Nature Genetics $\mathbf{2 6}$ 435-439.

Bailey CJ, Path MRC \& Turner RC 1996 Metformin. New England Journal of Medicine 334 574-579.

Barja G 1999 Mitochondrial oxygen radical generation and leak: sites of production in states 4 and 3 , organ specificity, and relation to aging and longevity. Journal of Bioenergetics and Biomembranes 31 347-366.

Bézaire V, Seifert EL \& Harper ME 2007 Uncoupling protein-3: clues in an ongoing mitochondrial mystery. FASEB Journal 21 312-324.

Biswas S, Chida AS \& Rahman I 2006 Redox modifications of protein-thiols: emerging roles in cell signaling. Biochemical Pharmacology 71 551-564.

Bordone L, Motta MC, Picard F, Robinson A, Jhala US, Apfeld J, McDonagh T, Lemieux M, McBurney M, Szilvasi A et al. 2006 Sirt1 regulates insulin secretion by repressing UCP2 in pancreatic beta cells. PLoS Biology 4 210-220.
Brookes PS 2005 Mitochondrial H+ leak and ROS generation: an odd couple. Free Radical Biology and Medicine 38 12-23.

Cannon B, Shabalina IG, Kramarova TV, Petrovic N \& Nedergaard J 2006 Uncoupling proteins: a role in protection against reactive oxygen species or not? Biochimica et Biophysica Acta 1757 449-458.

Ceddia RB, William WN Jr, Lima FB, Flandin P, Curi R \& Giacobino JP 2000 Leptin stimulates uncoupling protein-2 mRNA expression and Krebs cycle activity and inhibits lipid synthesis in isolated rat white adipocytes. European Journal of Biochemistry 267 5952-5958.

Chan CB \& Harper ME 2006 Uncoupling proteins: role in insulin resistance and insulin insufficiency. Current Diabetes Reviews 2 271-283.

Chan CB, MacDonald PE, Saleh MC, Johns DC, Marban E \& Wheeler MB 1999 Overexpression of uncoupling protein 2 inhibits glucose-stimulated insulin secretion from rat islets. Diabetes 48 1482-1486.

Chan CB, De Leo D, Joseph JW, McQuaid TS, Ha XF, Xu F, Tsushima RG, Pennefather PS, Salapatek AM \& Wheeler MB 2001 Increased uncoupling protein-2 levels in beta-cells are associated with impaired glucosestimulated insulin secretion: mechanism of action. Diabetes 50 1302-1310.

Dagon Y, Avraham Y \& Berry EM 2006 AMPK activation regulates apoptosis, adipogenesis, and lipolysis by eIF2alpha in adipocytes. Biochemical and Biophysical Research Communications 340 43-47.

Droge W 2002 Free radicals in the physiological control of cell function. Physiological Reviews 82 47-95.

Evans ZP, Ellett JD, Schmidt MG, Schnellmann RG \& Chavin KD 2008 Mitochondrial uncoupling protein-2 mediates steatotic liver injury following ischemia/reperfusion. Journal of Biological Chemistry 283 8573-8579.

Green K, Brand MD \& Murphy MP 2004 Prevention of mitochondrial oxidative damage as a therapeutic strategy in diabetes. Diabetes $\mathbf{5 3}$ S110-S118.

Halliwell B \& Gutteridge JMC 1999 Free Radicals in Biology and Medicine. Oxford: University Press.

Hardie DG, Hawley SA \& Scott JW 2006 AMP-activated protein kinase development of the energy sensor concept. Journal of Physiology 574 7-15.

Harper ME, Antoniou A, Villalobos-Menuey E, Russo A, Trauger R, Vendemelio M, George A, Bartholomew R, Carlo D, Shaikh A et al. 2002 Characterization of a novel metabolic strategy used by drug-resistant tumor cells. FASEB Journal 16 1550-1557.

Hong Y, Fink BD, Dillon JS \& Sivitz WI 2001 Effects of adenoviral overexpression of uncoupling protein-2 and -3 on mitochondrial respiration in insulinoma cells. Endocrinology 142 249-256.

Hurtaud C, Gelly C, Bouillaud F \& Levi-Meyrueis C 2006 Translational control of UCP2 synthesis by the upstream open reading frame. Cellular and Molecular Life Sciences 63 1780-1789.

Huypens P, Quartier E, Pipeleers D \& Van de Casteele M 2005 Metformin reduces adiponectin protein expression and release in 3T3-L1 adipocytes involving activation of AMP activated protein kinase. European Journal of Pharmacology 518 90-95.

Kirpichnikov D, McFarlane SI \& Sowers JR 2002 Metformin: an update. Annals of Internal Medicine 137 25-33.

Krauss S, Zhang CY \& Lowell BB 2005 The mitochondrial uncouplingprotein homologues. Nature Reviews. Molecular Cell Biology 6 248-261.

Ledesma A, de Lacoba MG \& Rial E 2002 The mitochondrial uncoupling proteins. Genome Biology 3 3015.1-3015.9.

Lee Y, Yu X, Gonzales F, Mangelsdorf DJ, Wang MY, Richardson C, Witters LA \& Unger RH 2002 PPAR alpha is necessary for the lipopenic action of hyperleptinemia on white adipose and liver tissue. PNAS 99 11848-11853.

Lenaz G 2001 The mitochondrial production of reactive oxygen species: mechanisms and implications in human pathology. IUBMB Life $\mathbf{5 2}$ 159-164.

Lenhard JM, Kliewer SA, Paulik MA, Plunket KD, Lehmann JM \& Weiel JE 1997 Effects of troglitazone and metformin on glucose and lipid metabolism: alterations of two distinct molecular pathways. Biochemical Pharmacology 54 801-808.

Matejkova O, Mustard KJ, Sponarova J, Flachs P, Rossmeisl M, Miksik I, Thomason-Hughes M, Hardie GD \& Kopecky J 2004 Possible involvement of AMP-activated protein kinase in obesity resistance induced by respiratory uncoupling in white fat. FEBS Letters 569 245-248. 
Matés JM, Pérez-Gómez C \& Núñez de Castro I 1999 Antioxidant enzymes and human diseases. Clinical Biochemistry 32 595-603.

Newsholme P, Haber EP, Hirabara SM, Rebelato EL, Procopio J, Morgan D, Oliveira-Emilio HC, Carpinelli AR \& Curi R 2007 Diabetes associated cell stress and dysfunction: role of mitochondrial and non-mitochondrial ROS production and activity. Journal of Physiology 583 9-24.

Nordberg J \& Arner ESJ 2001 Reactive oxygen species, antioxidants, and the mammalian thioredoxin system. Free Radical Biology and Medicine 31 $1287-1312$

Owen MR, Doran E \& Halestrap AP 2000 Evidence that metformin exerts its anti-diabetic effects through inhibition of complex 1 of the mitochodnrial respiratory chain. Biochemical Journal 348 607-614.

Pecqueur C, Alves-Guerra MC, Gelly C, Levi-Meyrueis C, Couplan E, Collins S, Ricquier D, Bouillaud F \& Miroux B 2001 Uncoupling protein 2 , in vivo distribution, induction upon oxidative stress, and evidence for translational regulation. Journal of Biological Chemistry 276 8705-8712.

Produit-Zengaffinen N, Davis-Lameloise N, Perreten H, Bécard D, Gjinovci A, Keller PA, Wollheim CB, Herrera P, Muzzin P \& AssimacopoulosJeannet F 2007 Increasing uncoupling protein-2 in pancreatic beta cells does not alter glucose-induced insulin secretion but decreases production of reactive oxygen species. Diabetologia 50 84-93.

Ramírez-Zacarias JL, Castro-Muñozledo F \& Kuri-Harcuch W 1992 Quantitation of adipose conversion and triglycerides by staining intracyctoplasmic lipids with Oil red O. Histochemistry 97 493-497.

Rial E \& Gonzalez-Barroso MM 2001 Physiological regulation of the transport activity in the uncoupling proteins UCP1 and UCP2. Biochimica et Biophysica Acta - Bioenergetics 1504 70-81.
Tong WH, Jameson GN, Huynh BH \& Rouault TA 2003 Subcellular compartmentalization of human $\mathrm{Nfu}$, an iron-sulfur cluster scaffold protein, and its ability to assemble a [4Fe-4S] cluster. PNAS $1009762-9767$.

Turrens JF 2003 Mitochondrial formation of reactive oxygen species. Journal of Physiology 522 335-344.

Wang MY, Lee Y \& Unger RH 1999 Novel form of lipolysis induced by leptin. Journal of Biological Chemistry 274 17541-17544.

Wieland O 1974 Glycerol UV method. In Methods of Enzymatic Analysis, pp 1404-1409. Ed. HU Bergmeyer. London: Academic Press.

Zhang CY, Baffy G, Perret P, Krauss S, Peroni O, Grujic D, Hagen T, Vidal-Puig AJ, Boss O, Kim YB et al. 2001 Uncoupling protein-2 negatively regulates insulin secretion and is a major link between obesity, B cell dysfunction, and type 2 diabetes. Cell 105 745-755.

Zhang CY, Parton LE, Ye CP, Krauss S, Shen R, Lin CT, Porco JA \& Lowell BB 2006 Genipin inhibits UCP2-mediated proton leak and acutely reverses obesity- and high glucose-induced b cell dysfunction in isolated pancreatic islets. Cell Metabolism 3 417-427.

Zhou YT, Shimabukuro M, Koyama K, Lee Y, Wang MY, Trieu F, Newgard CB \& Unger RH 1997 Induction by leptin of uncoupling protein-2 and enzymes of fatty acid oxidation. PNAS 94 6386-6390.

Received in final form 17 July 2008

Accepted 5 August 2008

Made available online as an Accepted Preprint

7 August 2008 